Maria Curie-Skłodowska University in Lublin

ORCID: 0000-0002-6804-4750

\title{
Sound design as narrative device in contemporary film: Subliminal soundscape of war and terror in Sicario (2015)
}

\begin{abstract}
The article provides an attempt to analyze selected characteristics of contemporary cinematic sound on the basis of the sound design in Sicario (2015, dir. Denis Villeneuve), which encompasses a digitally-processed orchestral score with originally texturized sound effects. I elaborate on the features of the sound design in Sicario in regard to production and composition. Moreover, I attempt to demonstrate the ways in which sound in Sicario, due to its characteristics, is outside any typical musical genre. Finally, the article focuses on sound effects which are used in an unusual way, for instance, so as to reflect characters' personalities. The analysis of Sicario demonstrates that a creatively and meticulously constructed sound design in film has the power to exceed its traditional, supporting role in the narrative.
\end{abstract}

Key words: film score, American cinema, sound design, soundtrack, Sicario, Denis Villenueve.

\section{Introduction}

Many cinematic masterpieces come from the era of silent film: The Great Train Robbery (1903), The Birth of a Nation (1915), Nosferatu (1922), The Covered Wagon (1923), Ben-Hur: A Tale of the Christ (1925), and City Lights (1931) are but a few examples. Thus, one may claim that sound is not a necessary component in cinema as film is considered primarily a visual medium. In his seminal publication on film sound Audiovision: Sound on Screen (1994), Michael Chion emphasizes the fact that "a film without sound remains a film; a film with no image, or at least a visual frame for projection is not a film" (143). Yet, David Lynch claims that "films are 50 percent visual and 50 percent sound. Sometimes sound even overplays the visual” (Zager 2015: 259). Sound design is capable of influencing the story to a great extent and its power in film should not be

1 Address for correspondence: Katedra Anglistyki i Amerykanistyki Instytutu Neofilologii na Wydziale Humanistycznym, Uniwersytet Marii-Curie Skłodowskiej w Lublinie, Plac Marii Curie-Skłodowskiej 4A, 20-031 Lublin, Poland. E-mail: lidiakniaz@gmail.com 
underestimated. Sound design in film is a tool, or, to put it differently, a narrative device which can propel the action, create interpretations of the visuals that otherwise would not emerge, and, as a result, modulate the overtone of the whole film.

Most commonly, sound supports narrative delivered by means of visuals. It may have a direct narrative role in the storytelling, by means of dialogs and the voiceover, or subliminal, when it is employed as a means of creating the mood and guiding the audience's attention. For instance, the so-called background music unconsciously affects the mood of the viewers as it corresponds with the atmosphere of a given scene. According to Gorbman, music in film should be invisible ${ }^{2}$ and inaudible, or rather heard unconsciously (73). Largely because of its invisibility, sound can evoke the aura of suspense or drama, especially when background music and sound effects are skillfully combined. Moreover, sound in film creates continuity, or links, between particular images as well as entire scenes.

According to Buhler et al. (2000), apart from the traditional functions of sound in film, sound is capable of achieving much more. Music's role is more complicated, or perhaps we should say more flexible. Music is sometimes very much involved with speech, as in a song performance or, less obviously, in dialogue underscoring (music that accompanies speech, playing "under" it). At other times, music interacts with sound effects, as in many science fiction and action-thrillers, where music and effects dovetail to create what often seems like a single continuous strand of sound. Music can also mimic sound effects (for example, percussion instruments were routinely used to generate sound effects during silent-film performances) (Buhler et al. 2000: 3).

In addition to interactions between music, dialogs, and sound effects mentioned by Buhler et al. (2000), sound may also correlate with images in a creative way - not only in order to support what is presented on screen or imply the emotional overtone of the scene, which is in line with traditional Hollywood practice mentioned above. It can propel action or supplement those elements of the narrative that are beyond the realms of cinematic possibility. ${ }^{3}$ In some ways, cinematic sound can also act independently from the film and "float in its own sphere, in effect outside the story and the physical world of the images" (Buhler et al. 2000: 3). One of the interesting examples of the unusual deployment of sound in relation to imagery can be found in in the torture scene in Quentin Tarantino's Reservoir Dogs (1992). Traditionally, the music's mood "must be appropriate to the scene" (Gorbman 1987: 78) but in Tarantino's films this principle is often violated. For instance, a gruesome scene is accompanied by a happy-sounding song "Stuck in the Middle with You" by Stealers Wheel, creating the grotesque effect, which is not characteristic of neo-noir crime thrillers. Thus, as the application of incongruent music in certain passages can introduce traces of other genres and strongly affect the perception of the scene as well as the viewer's emotional

2 The author refers to the "technical apparatus" of music that must not be shown on screen, unless the director wants the music to be "naturalized" as diegetic (Gorbman 1987: 73-75).

3 Sound can imply different temporal and spatial planes as well as represent what is impossible to be seen (for example, a deep, manly voice representing the voice of God). 
reactions (Bordwell 2002: 279), skillfully modulated sound in film can often influence the interpretation of the whole feature.

Even though film industry evolved and developed due to various technological advances, principles concerning film sound seem to remain relatively unchanged as the traditional pattern of film sound design is used in most Hollywood productions. Steven Shaviro argues that even though digital technologies contribute to the process of transformation of contemporary cinema, as far as sound is concerned, it "still often functions as it used to, providing added value for the moving images" in both contemporary Hollywood films and independent, art films (Shaviro 2016: n.p). At the same time, however, there are numerous films which employ sound in a creative way, for instance, when it serves different functions than expected or violates the principles of composition, mixing, and editing mentioned above (such as inaudibility or continuity).

In this essay I intend to demonstrate how sound in film can be approached non-schematically and used as a narrative device. The article analyzes the soundscape in Sicario (2015, dir. Denis Villeneuve), which encompasses a digitally-processed orchestral score with originally texturized sound effects. I elaborate on the features of the sound design in Sicario in regard to production and composition. Moreover, I attempt to demonstrate the ways in which sound in Sicario, due to its characteristics, is outside any typical musical genre. Finally, I focus on sound effects which are used in an unusual way, for instance, so as to reflect characters' personalities. The analysis of Sicario demonstrates that a creatively and meticulously constructed sound design in film has the power to exceed its traditional, supporting role in the narrative.

By many critics, Sicario (2015) is regarded as one of the best films of the year 2015, yet it did not receive any Academy Award. The film was nominated in three categories: Best Cinematography, Best Original Score, and Best Sound Editing. The director Denis Villeneuve is French-Canadian and his most popular feature films apart from Sicario include Prisoners (2013), Enemy (2013), and Blade Runner 2049 (2017). Interestingly, Villeneuve was not involved in the production of Sicario's sequel titled Sicario 2: Soldado (2018), which was directed by Stefano Sollima. Sicario's score was created by an Icelandic composer, Jóhann Jóhannsson (1969 - 2018). Apart from cinema, he composed for theater and was involved in his own music projects. His music can be characterized as neoclassical and electronic. Moreover, in his productions, Jóhannsson often employed dark drone sounds. He collaborated with Villenueve in Prisoners, where the soundtrack was dark and minimalistic. He also created the Golden Globe-winning score to The Theory of Everything.

Sicario has been praised by film critics who not only value its sound design but also Roger Deakins' cinematography and the performance of lead actors. The film was a commercial success with a box-office gross of 46,875,468 USD (IMDb). Sicario was released on Blu-ray with bonus content - A Pulse From the Desert: The Score of Sicario, Stepping into Darkness: The Visual Design of Sicario, Blunt, Brolin, Benicio: Portraying the Characters of Sicario, and Battle Zone: The Origins of Sicario. Sicario is an intense crime-thriller drama that is often compared to Steven Soderbergh's Traffic (2000), an Academy Award-winning drug cartel movie but is, in fact, very different. For one, Sicario does not portray drug use. Moreover, Traffic features an all-star cast in contrast to 
Sicario, in which there are only three leads. Villeneuve's film is suspenseful and tension-filled and "succeeds in evoking the menace, paranoia and ambiguity of the turf" (Rotella 2015: n.p.). The storyline involves an attempt to find one of the Mexican drug dealers but what audience experiences in terms of sound is neither traditional thriller or action film music, nor a typical Latino music-inspired score. Sicario features non-schematic, unconventional soundtrack which includes eighteen tracks the majority of which convey the atmosphere of sadness, terror and dismay.

\section{Research objectives}

In this article I am going to demonstrate how sound design in Sicario can be regarded as more autonomous than in a typical Hollywood movie. Sicario's originality in terms of sound pertains to the fact that the score combined with originally texturized sound effects does not only emphasize or make more precise what is seen on the screen but also reflects upon these elements of the narrative that are not yet displayed or will not be shown directly in images or dialogs. To explain this, I will first describe the general characteristics of Sicario's sound design - its composition, instruments employed, and sound production as well as the features of the score that, to an extent, are not in line with the conventional rules of the orchestral film sound. This inventiveness pertains, for instance, to the use of simple but at the same time multilayered ambient drone, achieved without synthesizers, which is unusual for this kind of sound. Secondly, I will focus on the originality of sound design in the film in reference to musical genres as the scoring in Sicario does not resemble a typical thriller or action movie music. Next, I will describe the ways in which the function of sound effects is extended in a creative way through skillful sound editing. Finally, I will analyze three selected scenes with interesting sound design: the opening sequence, the travel from Mexico to the cartel, and the underground tunnel scene.

Sicario's plot revolves around the escalating war on drugs on the Mexican-United States border. Kate Macer (Emily Blunt) is an idealistic FBI SWAT agent who volunteers to participate in a secret government mission about which she knows very little. Kate's personal objective is to find people responsible for the death of several of her colleagues. She is assisted by a senior officer Matt Graver (Josh Brolin) and a mysterious Mexican federal agent named Alejandro (Benicio del Toro), who is the eponymous Sicario 4 They aim to catch the cartel leader, Manuel Diaz (Bernardo Saracino), his brother Guillermo (Edgar Arreola) as well as the drug lord Fausto Alarcón (Julio Cedillo). In El Paso, Kate soon learns that her role in the team is not to provide tactical knowledge, as she has been told in the recruitment interview, but to testify that every suspicious action Matt and Alejandro take is legal and done "by the book". Kate feels isolated and morally torn as she discovers certain facts about Alejandro's assassin past and witnesses numerous law infringements

4 "Sicario" is a Spanish term for a professional hitman. The word is used particularly often when referring to hired killers in Latin American drug cartels. Sicarios, however, provide their services across Americas as well as in the Caribbean. 
during the mission. Unfortunately, in the end she is given no choice but to comply with the rules of people above her.

\section{Sicario's unconventional orchestral sonic palette}

The first feature of Sicario's score that can be regarded as non-traditional is that it utilizes a 65-piece orchestra, relying heavily on strings and percussion (tom-toms and military snare drums with the snare turned off) with occasional appearances of low brass and woodwind to create textural moods rather than melodic ones (Chagollan 2015). As mentioned by the composer in one of the interviews, there is also much of solo cello and multi-track cello and six-string bass guitar on the track which plays during closing credits entitled "Melancholia" (Grobar 2015). The instruments were used in an unusual way:

Like an aural Kraken, relentless gran casa, tuba, bass trombone and melting strings peel back the earth's surface and blanket the ears in menace. With a ritualistic, ancient-sounding beat, tracks like "The Border" and "Drywall" lock step to a seemingly inevitable demise, while "Target" puts Jóhannsson's deft string writing on display with the striking use of brutal col legno to disturb the pervasive bass drones (Armbrust 2015: n.p.).

Even though the soundtrack is dominated by classical instruments, it cannot be regarded as a conventional orchestral film score. Due to sound processing, the composer made the score appear more modern and experimental. He modified the quality of input sounds recorded for the purpose of the film in such a way that they sound almost like signals from the synthesizer. Orchestral music imitates the synthetic sound due to filters, plugins, and different effects layered over the recorded pieces. In one of the interviews, the composer explains how he achieved such non-standard sound:

The palette is very much based around percussion and it's based around orchestra, but the way I recorded the percussion and I recorded the orchestra was kind of unconventional. I recorded the orchestra in sections, and there's a lot of editing and processing of the orchestras. It's not like a live recording of the orchestra playing everything from bar one until the end. It was really a score that came together in the editing. So, there's a lot of processing. All of it is live recording, but they are all processed to different degrees - processed meaning edited and manipulated sonically. (Roberts 2005: n.p.)

Secondly, the sound in Sicario is percussive and pulsing. The director wanted Johannsson's score to feel like "a threat, coming from under your feet, deep under the surface of the scorched earth of the Chihuahua desert" (Chagollan 2015: n.p.). This threat can be called "The Beast" the name used in the score's track list. The sound resembles a heavy heartbeat in its repetitiveness. The score is intense, throbbing, and relentless - this tension is achieved exclusively by means of 
orchestral instruments as there are no electric guitars or synthetic basslines. The throbbing vibe is present from the very beginning of the film - from a barely audible sound that the audience experiences unconsciously, it crescendos to a peak pulse in the form of the SWAT vehicle sound crashing through the wall.

\section{Naturalistic ambient noise of the Mexican desert}

Another interesting feature of Sicario is its naturalistic and raw vibe, both in terms of visuals and sound. Villeneuve employs the technique of "dynamic realism" (Desowitz 2016). In his review, the film critic asserts: "The best way to describe the score and sound design for Sicario is 'dynamic realism' because of the calculated way in which director Denis Villeneuve sucks the viewer in, then slightly unnerves us with subliminal low-end bass before assaulting us with percussive hits". At the same time, there are numerous subtle sonic atmospheres reflecting the pulse of the desert, with a low-end bass in them. The score is raw because even when it is multilayered and digitally enhanced, it always reminds the audience of something real, organic which is an actual threat. Desowitz (2016: n.p.) claims that "it was over the top but was still in the realm of reality".

Yet another feature that makes Sicario original in terms of sound design is that it employs dark ambient drone that is unpleasant to the human ear, a design technique usually avoided in Hollywood productions. Sounds in Sicario are either irritating or they encompass too many extremes, for instance, as between quieter and loud sounds. As film's sound editor, Alan Robert Murray, said in one of the interviews, the soundtrack includes sounds that are annoying: from those comparable to sounds made by insects to a dentist's drill (Desowitz 2016). The contrasts between quietness and extreme loudness are substantial. It is heard especially in the scene when the agents' armored vehicle crashes through the walls. What precedes the sforzando-like impact is the relatively quiet pulse sound and almost complete silence in the house. ${ }^{5}$ Operating on substantial contrasts makes the sound design felt in the viewers' bodies rather than only heard.

Sicario's soundtrack cannot be regarded as a typical thriller or action film sonic design. In general, as "each genre represent[s] particular conventions for editing" (Dancynger 2018: 162), suspense and uncertainty are promoted in thriller films and are manifested by Hitchcock-like, high-tension scoring, whereas action films rely on fast-paced soundtrack and sonic intensified continuity. Sicario encompasses both genre conventions as it evokes excitement via the use of vibrating, subterranean score combined with the action film intensity of gunshots sounds.

\section{Scoring outside the genre}

In a typical thriller movie, tension and anxiety build gradually and culminate with tragic events. In Sicario the tension often crescendos but does not lead to any specific dramatic moment. It slows down for a second to reoccur with double strength. In other words, the action crescendos and

\footnotetext{
5 Sforzando indicates a forceful accent in music composition. For instance, it can take the form of a forte (loud) note after a sequence of quieter sounds.
} 
suddenly stops as if to "give the audience a second to recover" but after a while "it all hits you over the head with the [final] crescendo of the scene" (James 2016: n.p.).

When regarded as an action film, Sicario does not follow the rules of sonic intensified continuity in a conventional form. Sound design is indeed intense but in a different way. There is no denying that Sicario is tense in terms of sound (as noted earlier) but it concerns the overtone it creates and the atmosphere rather than the pace of sounds. There are no abrupt changes in soundscape, except the contrast between the silence in the house and the SWAT vehicle crashing through the walls or the subsequent explosion in Phoenix. However, it seems that continuous dark drone tune can be as intense as rapid jumping on sounds. That is why, in some sense Sicario's sound employs intensified continuity, which now is a norm in action films, but does it in a yet more unconventional way. In contemporary action films, intensified continuity is a standard and this pertains to sound as well. Sicario's sound can be characterized as entirely different since the drone is unchangeable, persistent, and moves from one scene to another. Sound effects are multilayered but are still rather continuous, relatively stable, and serve predominantly atmospheric purposes. ${ }^{6}$

One may thus draw a conclusion that sound in Sicario is, to a great extent, outside the musical genre. The film's sound design is in the borderland between thriller and action film. As mentioned by the composer, Villeneuve also wanted the score to be a "subtle war music" (Grobar 2015: n.p.). Even though the score is not an obvious thriller sound, it involves "sound textures that produce anxiety" (Desowitz 2016: n.p.).

Owing to the fact that Alejandro is the protagonist who wants to take revenge and fights violence with more violence, the film may be also viewed as a gangster movie which, to some extent, is reflected in the soundtrack since the emphasis is placed on the sound of the gunshot. Bordwell (2002) mentions the beat of the gunshot as one of the characteristics of gangster productions. He claims that "in a gangster film, a machine gun's fire creates a regular, rapid beat, while the sporadic reports of pistols may come at irregular intervals" (281). Sicario's sound design can be viewed as having certain gangster film-inspired elements.

\section{Sound design as a narrative tool}

Another feature that makes the sound of Sicario non-standard is the use of enhanced sound effects which reflect the characters' personalities. Sound effects are texturized in such a way that they characterize Kate's innocence and the mystery around Alejandro. In one of the interviews, Murray said that he wanted to keep scenes with Kate isolated in order to emphasize her loneliness. When it comes to Alejandro, along with revealing more facts about his background, his sound palette expands in time as there are "more undertones into his scenes in order to play to the uncertainty of his characters" (James 2016: n.p.). "Customized" sounds are here able to shape the narrative and contribute to the emotional side of the character's personalities.

6 Films that employ intensified continuity, often called chaos cinema, are often multilayered when it comes to sound in order to achieve the effect of incomprehensibility and chaos. 
As one of the most frequently occurring sound effects in Sicario gunshot sounds also play a significant role in portraying the protagonists as they match with the character of the shooter. The film's sound editor paid close attention to specific sound of the silencer:

Benicio (del Toro)'s character had a silencer, but we knew, once Benicio started on his secret mission, and the rage and the violence that was pouring out of him, we had to make a gunshot that would portray that even though it was a silencer. We ended up adding a lot of elements, like a synthesized bear trap to the mechanism of his gun. Things that would make the gun concussive, visceral, but still keep it in the silencer mode, so it was a lot of detail on the guns and painting them to match the specific characters in the movie (Blyth 2016).

Alejandro is a relatively silent, mysterious character and the tone of his silencer is in line with his personality. According to Murray, employing individualized sound design elements "can accent the mood or the subject in the scene without being obvious" (Blyth 2016: n.p.).

In addition, what distinguishes Sicario from the majority of traditional Hollywood films is its focus on sound editing and the way it exploits its narrative and atmospheric potential. Similarly to Terrence Malick's Red Thin Line (1998), where "every character's distinctive breathing sounds were recorded for use as ambient noise" (Bordwell 2002: 274), in Sicario some sound effects are used in unconventional ways. The most remarkable example of such originality in sound editing is the sound of the helicopter employed as part of the musicalized, ambient noise track. In contrast to the Beast's heartbeat-like pulse from underneath, the sound of the helicopter is the pulse from beyond. Distorted, science fiction-like, digitally processed helicopter sound becomes the element of the score. In other words, the sound effect "mimics" music in some way (Buhler et al. 2000: 3). Sicario's sound design plays on spatial relations between sounds effects that are underground, on the surface - like gunshot sounds or armed car engines, and in the sky. Sound effects that are present on the surface can be spatially divided into those that appear inside and outside. This distinction is visible especially in the Mexico border crossing shootout sequence that will be discussed in greater detail later in the article. As Kermode (2015: n.p.) notes, "Sicario uses private planes, public roads, and clandestine tunnels to slip back and forth across borders both moral and geographical". This vertical arrangement of narrative planes is enhanced by the use of sounds dedicated to a given spatial layer.

The score consists of almost uncontainable waves of orchestral sounds and sound effects which merge into an atmospheric whole. Murray's sound editing makes the score and sound effects blend seamlessly. Interestingly, the sound in Sicario is present inconspicuously, yet it creates the feeling of constant threat and uneasiness which is not very common even in thriller films. While, to most viewers, the sound is often not heard consciously, undoubtedly, its connotative effects are felt distinctly (Gorbman 1987). 


\section{Opening scene as an atmospheric prelude to terror}

The first passage in which sound evokes very strong emotions in an unusual manner is the opening sequence of the film. The film opens with a relatively fast but barely audible pulsating sound which appears as soon as the name of the studio and the production company is displayed. In time, the sound becomes louder and is accompanied by a digitally processed, high-frequency sound of cicadas as the viewers see the first shot. When the SWAT unit is moving towards the house, the sonic palette expands. Next, there is a quick shot from inside of the house with the sound coming from some television program. Then, in another shot, the viewers see another group of SWAT officers in a vehicle whose engine sound adds another layer to the sound track. It is the accelerating sound of the engine, alongside with the vibrating score, that creates the greatest tension which crescendos and reaches the highest point when the SWAT truck crashes through the walls. The final crescendo is preceded by a second of silence from the inside of the house which intensifies the effect of the crash, or, to put it differently, amplifies its volume. What is interesting, the tension is not completely released as the officers entering the house are loud enough to maintain it. When Kate enters the room and shoots at one of the Latino men, the sound of guns suddenly becomes the only sonic element in this scene. Then, there is a short period of silence. Isolating the gunshot sound from the rest of the soundtrack, again, is a way of intensifying the atmosphere. The pulsating vibe reoccurs when Kate's partner, Reggie Wayne (Daniel Kaluuya) notices what is behind the hole in the wall. After that, there is a shot outside the house, where the audience sees the characters vomiting which is caused by the smell of the corpses hidden in the wall. By means of sound effects and score, the tension in this fragment is consistently sustained. When the FBI officers come to the house, there is an atmospheric dark theme employed, which is audible along with the sound of the snapshots taken by the investigators who are photographing the corpses. Again, there is a shot from the outside of the house which is accompanied by Foley sound effects and a subtle percussive sound. After a short period of quietness, the tension rises, falls down for a short moment, and the unexpected loud sound of a bomb explosion appears. Kate exits the house and what she sees is a space full of dust. The score gets darker and overwhelming with every second. It accelerates, which may suggest another explosion, but the scene ends in an abrupt way and what follows is Kate's blood-stained and terrified face in the shower.

The pulse achieved by utilizing percussion appears from the very beginning of the film. Even though the sound is at first barely heard, it is felt subconsciously. The opening sequence has very strong dynamics as it plays on the distinction between loud and quiet volume as well as faster and slower pace. Thanks to sudden changes in volume and intensity of sounds, the quieter moments may be regarded as silent even if there is no complete silence at any point. The peak of crescendo is achieved by means of non-diegetic sound effects, rather than string section and percussion.

\section{7. "The Beast" of the US-Mexico border}

The second scene with interesting sound design is the travel from El Paso to Juarez. The characters go to Juarez to collect the brother of the cartel boss, Guillermo (Edgar Arreola). The passage, 
which starts when Alejandro folds his jacket and places it in the bag, is accompanied by the theme piece, entitled "The Beast." It is the sound that bridges a scene which takes place in the building and the following sequence of the journey. Before the visuals change, the sound already informs the audience about something which is not yet presented on the screen. What follows is the helicopter shot on the desert underscored by the subliminal low-end bass. "The Beast" expands and crescendos and, at some point, the focus from beyond switches to the road and the car convoy. In other words, the sonic point of view changes from beyond to the surface of the desert roads where "The Beast" is still clearly audible. ' In the exact moment when the cars cross the border, the sonic POV abruptly changes to the tense percussive score accompanied by musicalized helicopter sound and the viewers again see the road from beyond. When the convoy reaches Juarez, again, the audience hears the soundscape of the city: police horns, car engines, bumps on the road, some Mexican voices. When Alejandro says "Welcome to Juarez", the sound of his voice is definitely inside the car, as opposed to the sounds of the city outside the vehicle. Those contrasts between inside vs. outside are reflected faithfully, which makes the soundtrack very convincing and attention-grabbing. When the characters in the cars stop for a second to hear the sound of the shots audible from the distance, the strong percussive loop reappears signalizing another suspenseful scene. The cars accelerate, and so does the sound. The drivers communicate via CB radio which becomes another layer of sound. Moreover, in time the score is augmented with some Latino-sounding brass instruments. On its way, the convoy gets stuck in a gigantic traffic jam the size of which is visible to the audience thanks to another aerial shot accompanied by the helicopter sound. Inside the SUVs, the officers exchange information about the traffic jam at the border crossing. At some point, there is an order to get the weapons out as the Sonora Cartel members are in the traffic jam too. Outside, there is the sound of a barking dog and the non-diegetic, suspenseful theme piece. When the drug traffickers get out of the car, the convoy members engage in the same way. The shootout begins in which gunshot sounds and broken car windows are the only sound effects. When the intervention is over and the convoy can continue its journey, the score reappears for a while to fade out when the team reaches the prison.

The shootout sequence is regarded as a "master class in the production of tension" (Tallerico 2015). Instead of a car race that can be expected from an action film, the audience witnesses a monstrous and static traffic jam. Yet, due to seamless editing of shots by Deakins and intense sound editing by Murray, the seemingly static scene evokes "tortuous tension", and, consequently, it is considered one of the most suspenseful scenes of the year 2015 (Olsen 2015). In this sequence, the tension rises in time but in the moment of shooting there is a pause in the score to make the gunshot sounds resonate harder. In Juarez, gunshots in a way carry the sound of the city (James

\footnotetext{
7 In film production, point of view sound reflects the perspective of a character. According to Buhler et al. (2000), the use of POV sounds increases viewers' "identification with that particular character whose hearing the sound track mimics" (78). The term "sonic point of view" is also called "point of audition" and was discussed in detail in Chion's Audiovision (89-91) and Altman's Sound Theory, Sound Practice (251).
} 
2016). As mentioned by Murray, "they had to be realistic enough so they weren't too close, but still sound hostile at the same time" (James 2016). Bullets cut through the silence but when the sound stops, the orchestral pulse reappears. Such sound editing technique can be compared to holding one's breath, if one assumes that the score is in accordance to viewers' heartbeat and breath. When the team reaches the destination, namely the prison in Mexico, the pulse stops as there are no non-diegetic sounds.

\section{The unsettling pulse of the underground}

The third scene that deserves attention as it employs sound in an original way is the underground tunnel sequence. While it was praised by critics for its use of thermo- and night vision, it is remarkably significant in terms of sound effects that are attached to each device and are layered over the throbbing score. The passage starts when the team approaches a drug tunnel located in New Mexico desert. The group receives tactical information via an audio device and prepares for entering the tunnel. What accompanies the fragment are the tense string section sounds that can be compared to those present in Jaws (Merry 2015). When the group comes closer to the tunnel, the scene is presented from the characters' point of view as if through the night vision goggles. At this point, the sound changes - there are no non-diegetic sounds and what the audience hears are the characters' breaths and footstep sounds and some night vision signal. When thermographic camera is on, the audience hears quite different sound palette as the sounds are more distorted and evidently lower. There are also occasional shots from above which are also presented via the POV of thermographic camera where the sounds of pilot's voice, satellite footage, and helicopter engine are heard. The characters enter the tunnel. In time, the throbbing, subterranean sound is audible. It becomes another sound layer, apart from night and thermo-vision sound and dialogs. When the lights in the tunnel are on, the point of view changes - so does the sound as there are no sounds connected to night vision devices. The reverberant sound of gunshots becomes the most important element of the sound track. This sound moves the action forward since the drug traffickers hear the approaching threat before even seeing it. When Alejandro leaves the tunnel and shoots at the Latino man, non-diegetic sounds are not present anymore and from the atmospheric, unsettling underground vibe the scene changes to the sonic realism connected to the actual confrontation with the enemy.

The most powerful sound device employed in this passage is the characters' sonic point of view, which switches depending whether night vision or thermal imaging camera is used. The sound connected to night vision can be compared to science fiction-like, distorted high-pitched signal, whereas infrared camera vision is the subliminal, low-frequency sound. The scene features a considerable amount of off-camera gunshots which reverberate through the tunnel walls. Despite the limited space of a tunnel, the gunshot sounds do not lose their dynamics. Murray explains how gunshots function in this passage: "[when] a shooter is off camera and then moves into view, each gunshot gets more concussive and more elements are added to the gunshot so by the time you're close to the shooter the gun has totally changed, but you don't perceive it as a totally 
different gunshot" (James 2016: n.p.). The changeability of gunshot sounds in a relatively short underground tunnel sequence is what can be called "dynamic realism" in terms of sound (James 2016) which evokes "an increasing sense of concussive menace" (Desowitz 2016: n.p.).

\section{Conclusion}

To conclude, sound design in Sicario does not only provide the epistemic background as expected from a typical Hollywood production but is anchored to the narrative to such an extent that it propels the action rather than functions as its accompaniment. Sicario is an example of a contemporary movie where the soundscape functions as a character or narrator that adds new value to what is visible on screen. By means of raw percussive bass combined with well-chosen sound effects, the sound design in Sicario reflects the dry pulse of the Mexican border zone as well as personality traits of the characters immersed in the brutal reality of the drug war. The sound here interacts with visuals just as the score interacts with sound effects, which is rather unconventional for a Hollywood movie.

As the film presents the problem of drug trade on the borderlands from an unusual angle and attempts to present the complexities of the problem, the sound design functions in a similar way - it does not merely flow on the surface of the narrative. Sicario's evocative sound design goes deeper and creates a permeating sound core where particular gunshots and string sections are the muscles that stretch and contract in the heartbeat-like rhythm of "The Beast". This wild pulse alongside with the suppressed sound of panic and paranoia permeates the whole film, that is why it can be said that sound in Sicario "exceeds narrative motivation" (McQueen 2013).

\section{References}

Altman, R. 1992. Sound Theory, Sound Practice. New York: Routledge.

A Pulse from the Desert: The Score of Sicario. 2016. Short, Action.

Armbrust, D. 2015. “Jóhann Jóhannsson's Relentless, Ritualistic 'Sicario' Soundtrack.” WQXR (14 December 2015). http://www.wqxr.org/story/johann-johannssons-relentlessritualistic-sicario-soundtrack / ?utm_source=sharedUrl\&utm_medium=metatag\&utm_ campaign=sharedUrl

Blyth, A. 2016. Alan Robert Murray on 'Sully,' and creating Benicio Del Toro's gunshot sound for 'Sicario.' https: / / www.yahoo.com/tv/alan-robert-murray-sully-creating-184853799. html (Accessed: 16 February 2016).

Bordwell, D. 2002. Intensified continuity visual style in contemporary American film. Film Quarterly 55 (3): 16-28. https: / / doi.org/10.1525/ fq.2002.55.3.16 (Accessed: 19 May 2016). Bradshaw, P. 2015a. Sicario review: Emily Blunt cracks the cartel in a white-knuckle thriller. The Guardian. http: //www.theguardian.com/film/2015/may/19/sicario-review-emilyblunt-thriller (Accessed: 19 May 2016). 
Bradshaw, P. 2015b. Sicario review - Emily Blunt at the sharp end in war on drugs. The Guardian. October 8, 2015. http: //www.theguardian.com/film/2015/oct/ ๑8/sicario-review-emily-blunt-at-the-sharp-end-in-war-on-drugs (Accessed: 18 May 2016).

Buhler, J., Flinn, C. \& Neumeyer, D. (eds). 2000. Music and Cinema. $1^{\text {st }}$ edition. Hanover, NH: Wesleyan.

Chagollan, S. 2015. 'Sicario's' ominous score aims to match film's brutality. Variety (blog). September 16, 2015. http://variety.com/2015/artisans/production/sicario-score-johann-johannsson-1201594496 / (Accessed: 17 May 2016).

Chion, M. 1994. Audio-Vision: Sound on Screen. 14th edition. New York: Columbia University Press.

Dancynger, K. 2018. The Technique of Film and Video Editing: History, Theory, and Practice. 6th edition. New York: Routledge.

Desowitz, B. 2016. How they made the percussive sound and score for Oscar nominee 'Sicario.' Thompson on Hollywood. February 17, 2016. http: / / blogs.indiewire.com/thompsononhollywood/how-they-made-the-percussive-sound-and-score-for-oscar-nominee-sicario-20160217 (Accessed: $2 \odot$ May 2016).

Giardina, C. 2015a. How Roger Deakins mastered shooting in the dark for 'Sicario.' The Hollywood Reporter. November 26, 2015. http://www.hollywoodreporter.com/behind-screen/howroger-deakins-mastered-shooting-842555 (Accessed: 19 May 2016).

Giardina, C. 2015b. 'Sicario' editor Joe Walker outlines how he cut the cartel thriller. The Hollywood Reporter. December 10, 2015. http: / /www.hollywoodreporter.com/behind-screen/sicario-editor-joe-walker-outlines-847890. (Accessed: 5 June 2016).

Gorbman, C. 1987. Unheard Melodies: Narrative Film Music. London: BFI Pub., Bloomington: Indiana Univ Pr.

Grobar, M. 2015. 'Sicario' composer Johann Johannsson on creating propulsive sound of drug war drama - AwardsLine. Deadline (blog). December 24, 2015. http: //deadline.com/2015/12/johannjohannsson-sicario-composer-oscars-best-score-1201664692/ (Accessed: 25 May 2017). James, D. 2016. Contender - sound editor Alan Robert Murray, Sicario. Below the Line (blog). February 2, 2016. http://www.btlnews.com/awards/contender-portfolios/contendersound-editor-alan-robert-murray-sicario/ (Accessed: 6 May 2016).

Kermode, M. 2015. Sicario Review - Emily Blunt's Star Quality Lifts Mexican Drugs Thriller. The Guardian. October 11, 2015. http://www.theguardian.com/film/2015/oct/11/sicarioreview-emily-blunt-star-quality-lifts-thriller.

McQueen, A. 2013. 'Bring the Noise!': Sonic intensified continuity in the films of Edgar Wright. Project MUSE 7 (2): 141-65.

Merry, S. 2015. Stressful music, carnage and Oscar Buzz: Why 'Sicario' is the new 'Jaws.' The Washington Post, October 5, 2015. https: //www.washingtonpost.com/news/arts-and-entertainment/wp/2015/10/05/stressful-music-carnage-and-oscar-buzz-why-sicariois-the-new-jaws / (Accessed: 2 July 2016). 
Olsen, M. 2015. Tension Crackles across the many borders of 'Sicario.' Los Angeles Times. September 17, 2015. https: / / www.latimes.com/entertainment/movies/la-et-@918-sicario-review20150918-story.html. (Accessed: 23 July 2016).

Roberts, S. 2015. Composer Johann Johannsson talks Sicario, Denis Villeneuve. Collider (blog). September 29, 2015. http://collider.com/composer-johann-johannsson-sicario-interview/ (Accessed: 29 May 2016).

Rotella, S. 2015. Sicario's dirty war on Mexican cartels is not yet reality. ProPublica. October 23, 2015. https: / / www.propublica.org/article/sicarios-dirty-war-on-mexican-cartels-isnot-yet-reality (Accessed: 2 June 2016).

Shaviro, S. 2016. 3.4 Splitting the atom: Post-cinematic articulations of sound and vision. POSTCINEMA (blog). April 11, 2016. http: / / reframe.sussex.ac.uk/post-cinema/3-4-shaviro/ (Accessed: 12 July 2016)

Tallerico, B. 2015. Sicario movie review \& film summary (2015) | Roger Ebert. http: / www.rogerebert.com/reviews / sicario-2015. (Accessed: 3 June 2016)

Zager, M. 2015. Writing Music for Commercials: Television, Radio, and New Media. 3 edition. Lanham, Maryland: Rowman \& Littlefield Publishers.

\section{$* * *$}

Lidia Kniaź is a $\mathrm{PhD}$ candidate at Maria Curie-Skłodowska University in Lublin, Poland, and a 2016 winner of the 2nd Prize in Poland's contest for the Best MA Thesis in American Studies. Her research interests include science fiction music videos, Afrofuturism, and sound design in film. She is currently working on her dissertation on Afrofuturist music videos. 